of about the same date, such as seems to have been in use in most Roman kitchens. It is of coarse white ware, roughened on the inside with grit. It bears the stamp of the maker-Albinus of Lyons. Samian ware, so-called, is represented by, among other pieces, three bowls and some fragments of the more elaborate decorated work. There are several of the leather soles of the Roman shoes which are frequently found in London in a good state of preservation. Pottery forms a large proportion of the medieval exhibits ; but there are also examples of tradesmen's tokens, bronze 'jettons' or 'casters', used in keeping accounts and making calculations in the Middle Ages, wine bottles, and other domestic objects, including examples of the familiar clay smoking pipes of the seventeenth and eighteenth centuries.

\section{University of Prague}

Dr. Gustav Ortner, of the Institut für Radiumforschung, Vienna, writes in connexion with the paragraph on the future of Czechoslovakia in NATURE of October 8, p. 637, that it gives an inadequate idea of the historical development of the universities in Czechoslovakia. He continues, "the University of Prague [was] founded by the German Emperor Karl IV in 1348 and so is the most ancient German university. It was only in the course of the nineteenth century that lectures in Czech were given and in 1882 an independent Czech University was separated off from it. In 1920 the ancient name of 'KarlsUniversität' of the German University was transferred to the Czech University. ... O" Obviously it was not possible to go into details in a brief paragraph, but the facts were correctly given. It is true that Charles IV (Karl in German, Karel in Czech) was not only king of Bohemia but Holy Roman Emperor as well, yet it was as king of Bohemia that he founded the University of Prague, and the 560th anniversary of his death was celebrated there on November 27. The Czech character of the University was emphasized by his son, Wenceslas IV, in a special decree in 1409. The University of Vienna dates from 1364, and that of Leipzig from 1409, having been founded in Saxony as a challenge to Prague at a time when Czech was used as well as Latin, which was naturally the main literary language there as everywhere at that time. Thus, the University of Prague is the oldest in Central Europe, but by its foundation it cannot be considered a German university. From 1620 until 1882 it was styled the Charles-Ferdinand University. Afterwards Prague had two universities, the Charles (Czech) and the Ferdinand, or now simply, German University. Another correspondent refers at length to a number of distinguished Prague biologists and the mathematician, Bolzano, not mentioned in the further article, in Nature of November 26, p. 942.

\section{Mathematical Films}

ThERe has been a considerable increase of interest recently in the use of films for mathematical teaching. The Mathematical Gazette of October 1938 and the American Mathematical Monthly of the same month both contain reviews of such films, but the majority of the films mentioned are not available in Great Britain. Mr. B. G. D. Salt, of 5 Carlingford Road, Hampstead, N.W.3, sends us a list of five films that are now available and can be obtained from him. Two of these are geometrical, dealing respectively with the theorem of Pythagoras concerning rightangled triangles, and with the sum of the angles of a triangle. Two others deal with differential equations, by a method devised by Robert Fairthorne, one for the differential equation of free harmonic motion, and the other for harmonic motion when the vibrations are forced. The principle for free vibrations was explained in NATURE of October 24, 1936, and that for forced vibrations is somewhat similar. These four films occupy one reel each.

The fifth film, entitled "A Hypocyclic Motion", which shows much more than its title suggests, is sold divided into three short reels. In reel 1, a rigid bar moves with its end on two fixed straight lines. The instantaneous centre of rotation traces out the body and space centrodes, and it is shown that the motion can be produced by the body centrode rolling on the space centrode. In reel 2 , points on the circum. ference of the rolling circle trace out diameters of the fixed circle, showing simple harmonic motion. The motion is also shown to be derivable by another epicyclic motion. In reel 3, we have an ellipse described as in the tool known as the elliptic chuck, also Oldham's Coupling, and the four-cusped hypocycloid. Finally, the reel shows the generation of an envelope by a moving line. The two geometrical films are on $16 \mathrm{~mm}$. only, but the other three can be obtained on $35 \mathrm{~mm}$., $16 \mathrm{~mm}$., or $9.5 \mathrm{~mm}$. There is still considerable doubt as to the part that films should play in mathematical education. The Mathematical Association has set up a film sub-committee to consider the subject. Anyone who has suggestions to offer, especially suggestions for specific films, should send them to Miss M. Punnett, 17 Gower Street, W.C.1. Approved suggestions will then be passed on to the manufacturers.

\section{British Bird Song Survey}

THE preliminary report on the first year's record of the bird song survey in the British Isles, carried out under the auspices of the British Trust for Ornithology during August 1937-August 1938, states that some eighty observers took part and there are records of the song period of the mistle-thrush from 52 localities, the song thrush from 76, blackbird from 74, chaffinch 63, yellowhammer 35 and skylark 48 . Sussex and Cheshire were well covered, but there were only two sets of records from Ireland, three from Scotland and one from Wales, and none from Cormwall, Dorset, Lincolnshire, East Yorkshire, Durham, Northumberland, Stafford, Shropshire or Hereford. 10-15 per cent of the records were very incomplete, being made over less than nine months, and scarcely a quarter of the observers lived in the country and could listen to bird song throughout the day. One observer suggests that by no means all the male birds of even these common species sing at all, so that future observations are to give close 